\title{
Growth Strategy and Performance of Selected Small and Medium Scale Enterprises in Anambra State, Nigeria
}

\author{
NWAELE. SYLVESTER KELECHI ${ }^{1} \&$ EGBUTA OLIVE. $\mathrm{U}^{2}$
}

\author{
Management Science, School of Business \\ Babcock University \\ Ilishan Remo \\ Ogun State, Nigeria
}

\begin{abstract}
In numerous sectors, the intense global competition has resulted in a wave of mergers and acquisitions over the years. A company with the aim to remain in the race almost has to merge, buy, orally with another company. Another alternative is to expand and grow the organisation internally, e.g. diversifying, building completely new mills to new markets. Lack of adopting valid and effective growth strategies has been a problem for small and medium scale enterprises leading to a decline in their overall performance. The study thus evaluated the effect of growth strategy and performance of selected small and medium scale enterprises in Anambra State, Nigeria.

The study employed a cross-sectional survey research design. The Cross-Sectional survey research design was adopted to obtain information from the focus population concerning the current status of the phenomena through primary data collection. The population for the research comprised of selected small and medium scale enterprises that were registered with SMEDAN and operate in Anambra State, Nigeria. The total number of registered SMEs with SMEDAN as of 2017 was 1,504. The sample size for the study was obtained using the research advisors table. Based on a confidence level of 95 and the level of precision of $5 \%$ the samples size is 322 but with the addition of $30 \%$ for non-response rate, the sample was given thus as 418. The addition of $30 \%$ to the sample size is to ensure that the response rate of the study is attained significantly. Making provision for the non-response rate allows the researcher to improve the rate of response for the survey.

The findings of the study revealed that there is a relationship between the two variables. Concerning the exact effect of the penetration strategies on market share, the $r^{2}=0.452$ shows the extent to which the penetration strategies explain the variation in market share of the selected small and medium scale enterprises. The coefficient also revealed that there is a positive relationship between the penetration strategies and the market share of the selected small and medium scale enterprises
\end{abstract}

The study recommended that penetration strategies should be given adequate attention and consideration by different small and medium-sized enterprises to reap benefits. Penetration strategies which are an effective tool for achieving better performance over rival firms should be adequately implemented by the organization.

Keywords: Growth Strategy, Performance, Market Strategy, Penetration Strategy, Small \& Medium Scale Enterprises.

\subsection{INTRODUCTION}

Small and Medium Scale Enterprises (SMEs) are relevant to the economic development of every nations, especially Nigeria. They are of utmost importance to business managers, owners and even policymakers who leverage on their relevance to create policy programs that drive change. Scholars concludes that SME performance is the lifeblood of the economic scheme by contributing to 
the economic growth of the country. Small and medium-sized businesses (SMEs) play a vital role in the economic development of nations. This is because, SMEs mobilise resources otherwise left out of the mainstream formal economic mobilisation channels, and provide the necessary platform for take-off into large scale modern production by many indigenous Nigerians. The contribution of small and medium-sized enterprises (SMEs) to employment, growth and sustainable development is widely acknowledged. SMEs by number, dominate the world business stage. Although up-to-date data is challenging to obtain, estimates suggest that more than 95 percent of enterprises across the globe are SMEs, accordingly accounting to approximately 60 percent of Private-sector employment. Despite the significant contributions of SMEs to growth, their performance has been a challenge as it is on record that some SMEs fail to grow leading to declining in performance and some go into extinction before their fifth anniversary.

Globally, Small and Medium-Scale Enterprises (SMEs) have increasingly become a powerful and critical engine for both economic growth, social development and are seen as change agents in today's rapidly growing, volatile and dynamic competitive business environment [47]. Despite the contributions of SMEs to every country's economy, they are facing several challenges that hinder their performance in general. For instance, In Iraq, Korea, Malaysia as well as other countries around the world, SMEs are faced with difficult challenges such as low capacity, low economies of scale, poor market performance, declining profitability, inconsistency in government policies, access to financial support, poor sales and infrastructural inadequacies [11]. These factors have hindered their performance in various degrees.

SMEs represent the considerable majority of the businesses in the United States of America. They generate USD 4 trillion in annual economic output, 68 million jobs and one-third of all [21]. This provides approximately 75 percent of all net jobs added to the economy and 99.7 percent of all employees. There are approximately 23.4 million SMEs in the USA, accounting to 98.7 per cent of all firms in the US and contribute 41 percent of the total sales [34]. These challenges faced by SMEs in the United States of America bothers on the following: poor rules, poor strategic projections, administrative bottlenecks that often lead to cutting corners and creative accounting to appear profitable before investors.

In India, 13.5 Million SMEs were employing about 42 Million people [23]. It is further observed that the SMEs sector produces over 6000 products ranging from traditional to high-tech items. The major export products include ready-made garments, chemicals and pharmaceuticals, engineering foods, processed foods, leather products and marine products. The challenges facing SMEs in India include the following: lack of skilled workforce, inadequate credit assistance, irregular supply of raw material, absence of organised marketing, lack of machinery and equipment [20].

Small and Medium Enterprises in the sub-Saharan African region are faced with a number of constraints: technological backwardness, inadequate human resource skills, weak management systems, poor leadership and entrepreneurial incapacities, unavailability of appropriate and timely information, insufficient use of information technology, low product quality and many more; and as a result; there exists a low level of performance amongst them [28-16]. In Kenya, despite the critical role played by the SMEs in the country, most of the business start-ups are faced with many challenges where over $90 \%$ of the businesses fail even before their third year [6]. Further, Koech and Were (2006) observed that in Kenya, very few enterprises have grown into large formal organisations, an adverse scenario that is common among SMEs. In Botswana, research also found that despite the strategic role that SMEs play in the national development, their performance is still marred by a host of limiting factors that threaten their survival [27]. In Ghana, SMEs encounter problems related to leadership, a decline in profitability and market share [27]. These challenges have led to the inability of SMEs to record higher performance, profit and growth [27].

In Nigeria, Small and Medium Scale Enterprises (SMEs) have not made the desired impact on the Nigerian economy despite all the efforts and support of succeeding administration and government gives a cause for concern [38]. It emphasises the belief that there exists fundamental issues or problems, which confront SMEs but which hitherto have either not been addressed at all. SMEs in Nigeria are faced with fundamental and far-reaching issues such as inadequate, inefficient. At times, non-functional infrastructural facilities, which tend to escalate costs of operation as SMEs are forced to resort to private provisioning of utilities such as roads, electricity, transportation, communication, bureaucratic bottlenecks and inefficiency in the administration of incentives and support facilities provided by the government [10]. These factors affect the prospects for growth of these SMEs in a negative manner. Irregular policies often create gridlocks for these small businesses as they struggle to penetrate the market and sell their products, often improper conceptualisation leads to poor market and product development, and low level of resources ownership and accumulation often hinder their chances of diversification. These issues thus form the basis for this study.

\subsection{Problem Statement}

In Nigeria, SMEs are seen to be a strong force for economic growth and development and have contributed significantly to the improvement of standard of living, however, the sector continues to face many challenges that keeps SMEs at a disadvantaged position compared to other nations. These include unfavourable policy environment, inhibitive legal and regulatory framework, limited access to information, limited access to markets, inadequate access to skills and technology, insecurity of land tenure, poor 
access to infrastructure, insufficient know-how and inadequate linkages with larger enterprises, lack of access to credit facilities and corruption. These issues observed have been seen as impediments to the growth of SMEs, especially in Nigeria.

Several authors [44-29-10] have carried out studies on market penetration and how it relates to the company's market share within the industry. Sidi, Haim \& Abdl (2017) in their research about the relationship between market penetration and SME performance, revealed that market penetration strategies had not been adopted fully by firms. Hence the need to further make this the purpose for further research as very few researchers have worked on market penetration and its effect on the market share of an SMEs [47]. It is observed that SMEs in Nigeria fail at market penetration due to stiff competition, low economies of scale, scarce resources and weak management capacities to take advantage of the opportunities that exist in such strategy. SMEs in the country are experiencing difficulties and problems to growth and development that are not just as a result of the current economic decline. SMEs from both emerging and industrialised nation realise similar market situations, which involve the absence of competitiveness, lack of personnel management, information asymmetry challenges, and market instabilities (52). These observed challenges to market penetration have led to declining in market share of these SMEs, loos of customers and eroding goodwill as they are unable to keep up with the intricacies that exist in the market.

\subsection{LITERATURE REVIEW}

\subsubsection{Growth Strategy}

Growth in respect to business represents an increase and development in terms of quantity and quality. Quantitative growth is described as, depending on types and properties of the business, numeric growth or volume-wise growth in resources or capacity, Sales Income, Product range and market size, the number of employees and amount of cash, size of investments. On the other hand, qualitative growth is related to quality improvements in business. This growth is relatively challenging to formulate in terms of numbers [40]. Growth increases the overall business performance, including sales, assets base, employee retention, goodwill, and increases business profits that drive investment and economic development. Business growth, as earlier mentioned, entails introducing new products and services or adding new features to existing products.

Growth strategy refers to the strategic plan formulated and implemented for expanding a firm's performance and hence gaining a competitive advantage over other firms [35]. Formulation and implementation of growth strategies are very crucial when it comes organisational performance, and it is, therefore, important for an organisation to find out which growth strategies are relevant and applicable to its industry so that they can be significant. In this case, commercial printing firms need to find out which growth strategies are relevant and useful to this industry as they formulate and implement their growth strategies if they are to be effective. Lack of such understanding may result in poor or underperformance of such companies. A Strategy generally involves setting goals, determining actions or patterns to achieve the goals, and mobilising resources to execute the actions. It is a description of how goals will be completed by the resources that are available and adequately allocated. It is also an emerging pattern of activity that organisation adapts to its environment or to compete involves both strategic planning and thinking. It is against this background and various that McKeown (2011) summaries strategy as a situation that shapes the future and the human attempt to get to desirable ends with available means. Odunayo (2018) defined growth strategies as the meeting of customers' requirements (needs, wants, desires, preferences, and buying patterns) with the capabilities of the organisation, based on the skills and resources available to a business organisation.

Growth Strategies could follow one of three modes: planning, entrepreneurial, and adaptive. Kipley, Lewis, Helm-Stevens, and Ansoff (2019) further stressed that the right growth strategy choice depends on contingency variables such as the size and age of the organisation and the power of key decision-makers. They also supported that a company's growth strategies indicate the choices its managers have made about how to attract and place customers. Stubbs (2019) believed that regardless of whether company's strategies change gradually or shift, the critical point is that a company's current system is temporary (temporary competitive advantage) and on trial, pending new ideas for improvement from management due to changing business environment acting on them that warrant strategic adjustment and needs to be sustained over time (competitive advantage). Growth strategies common to all types and sizes of businesses include the following: market penetration, market development, product development, diversification. This study adopts these strategies.

\subsubsection{Penetration Strategies}

Market penetration is one of the Igor Ansoff growth strategic decision, that is aimed at creating more shares for the existing market [53]. The strategy concentrates on gaining market competitiveness by having a sustainable market share in the market [17]. Market penetration is a process in which the firm influence its strategies to increase its business activities, through maintaining sales to current customers as well as looking for a potential customer to increase the volume of sales, without changing its prime market and product strategy. According to Slater and Narver (2016) Market Penetration Strategy involves organisations, products and services that are sold in existing markets. Therefore, the goal of the strategy for market penetration is to concentrate on 
increasing the current product or service market share on the existing market. According to Levay, Drossinos and Thiel (2017), organisations adopt a Market Penetration Strategy to increase income from sales without altering the products or services. Therefore, it is argued that after assessing the multiple alternatives and their intrinsic hazards, the selection of penetration mode is made at the company level and is, therefore, a strategic decision for the company. Firm size matters in this regard to industry level on how it can penetrate the market environment [26]. It may seem evident that more prominent organisations may use size to have effectiveness over smaller size firms [3] with the concept of creating significant hurdles for entry to other rivals.

In a growing market, simply maintaining market share will result in growth, and there may exist opportunities to increase market share if competitors reach the capacity limit. However, market penetration has limits, and once the market approaches saturation point, another strategy must be pursued if the firm is to continue to grow. Sije and Oloko (2013) examined the relationship between penetration and the performance of SMEs in Kenya and found out that there was a strong positive correlation between penetration strategy and performance of SMEs. Pearce and Robinson (2012) enumerate specific options under the penetration strategies (increasing use of the current product in the current market). Market penetration has also been referred to as market share. It is the measure of the percentage of sales volume an existing product or business achieves about its competitors. Therefore, to increase market penetration businesses can employ some strategies to take sales from its competitors. Strategic managers spend much time and strength in analysing how to transform their product market strategy to increase performance.

Kyalo (2016) states that market penetration happens when an organisation enters or infiltrates its current market with current items. The ideal approach to accomplish this is by picking up a competitor's customers. This is an internal growth strategy where an organisation uses its resources to grow. The business entity within a specific market is interested in expanding its business within the same market by increasing its customer base or market share. Therefore, an organisation needs to come up with different ways to draw in new customers or persuade its current customers to consume more of the existing product, to use it more often or to use it in new ways. This, in turn, helps the company grow its market share within the existing market. However, market penetration has limits, and once the market approaches saturation point, another strategy must be pursued if the firm is to continue to grow [55].

\subsubsection{Performance}

Organisational performance has been defined by various authors with different approaches which are influenced by multiple context, language, observation and experiences. Shafiq, Lasrado, and Hafeez (2019) portray organisational performance as the result of activities carried out for business and is concerned with the general efficiency of productivity. Al-Kalouti, Kumar, Kumar, Garza-Reyes, Upadhyay, Zwiegelaar, and Kumari (2019) added that organisational performance as the way of measuring the performance of an organisation in terms of determining whether or not an organisation is achieving its objectives. More so, Reuben, Obura, and Oginda (2019) contributed that organisational performance is the overall health of an organisation. On the other hand, Rao, and Zaidi (2019) referred to the organisational performance as a measure of how efficiently managers use resources to satisfy customers and achieve organisational goals - broadening the conceptualisation of organisational performance. Connecting the definitions, Ngoc-Tan, and Gregar (2019) added that the performance of an organisation is not only measured financially but also measured by non-financial processes such as employee development, customer satisfaction, job satisfaction and efficient organisational internal processes.

Performance within an organisation can be evaluated as the process of assessing the organisation's progress in achieving its goals and objectives [19]. The assessment can be in financial or non-financial measures like profitability growth, brand relationship and corporate image. The idea of measuring performance is not only to identify the current performance of the business, but it is also how the business can perform better in the future in line with its strategic objectives [36]. Performance measurement is therefore crucial since it measures the effectiveness of the organisation's operations that contribute in creating value to stakeholders as well as the efficiency of the transformation of resources into products [19].

Performance is perceived to be the attainment of a firm's economic goals. It is an extent to which a company financial or nonfinancial health over a while is measured [13]. It is an economic action used to generate higher sales, Return on Assets and worth of a business entity for its shareholders through managing its current and non-current assets, financing, equity, revenues and expenses [4]. Firm performance relates to the various subjective measures of how well a firm can use its given assets from the primary mode of operation to generate profit. Eyenubo (2013) stated that it is the success in meeting pre-defined objectives, targets and goal within a specified time target. A firm's performance is critical to its health and survival [18]. Farah and Nina (2016) stated that the main purpose of performance is to provide complete information to shareholders and stakeholders to encourage them in making decisions. 


\subsubsection{Market Share}

Market share can be defined as a fraction of an industry that a company control. It is also the overall sales of a market that a particular company earns in a given period. To obtain the percentage value of a market share, simply divide the company's sales in a given period by the sum of the industry's sales over the same period [5]. Market share is the percentage of the total sales volume in a market captured by a brand, product, or company. According to Victor (2014), market share is a measure of the consumers' preference for a product over other similar products. A higher market share usually means more significant sales, lesser effort to sell more and a substantial barrier to entry for other competitors. Lee (2018), further stated that a higher market share also means that if the market expands, the leader gains more than the others. A market leader - as defined by its market share - also has to expand the market, for its growth. According to Folarin (2013), it is the specific percentage of total industry sales of a particular product achieved by a single company in a given period.

Market share of a product as defined by Best (2015) is the percentage of current market demand obtained by a business. According to him, market share is used by businesses to determine their competitive strength in a sector as compared to other companies in the same industry, and it also allows an organization to accurately assess their performance from year to year noting if a particular company is closing better or worse compared to other companies in the same industry. But Sliden (2017) defined market share as the portion or percentage of sales of a particular product or service in a given region that are controlled by a company. Managing market share, therefore, is an essential aspect of managing a business. However, Schwalbach (2018) said that market share reflects the current competitive position a company attains in the market. He claimed that companies with high market shares are considered to satisfy customers' needs better, and therefore, enjoy a competitive advantage vis-à-vis their smaller counterparts.

Market share is the consequence of efficiency rather than its cause. Differences in profitability among firms are due to higher efficiency. Efficient firms obtain a large market share and earn high profits induce a causal association between size and profitability [56]. Firms offering products that offer customers more excellent value enjoy gains in market share. Better managed firms that have a competitive advantage grow faster than rival firms. Firms with superior skill and foresight gain market share through lower prices or better products [7]. Similarly, Hambrick and MacMillan (2009) suggested that market share is more important for tiny and substantial firms. Woo and Cooper (2011) found that some low market share firms were successful and, thus, high profitability is not limited to large firms only.

Market share provides a clear indication of a firm's standing in its market. According to Darmon (2013), market share measures a company's market penetration, and, to some extent, the selling unit is responsible for it. Darmon (2013) stated that competitive sales performance constitutes a natural benchmark for evaluating selling units' market performances. In other words, it is essential to account for the evolution of the competition's sales levels for evaluating selling unit market performance. When territory sales, industry sales, market shares, and profit variations are considered jointly, they provide a complete assessment of a selling unit market performance. Various market conditions require different efforts and abilities [14]. Increasing or even maintaining sales volume and profits in a declining market is indicative of higher market performance than the same achievement in a fastexpanding market.

\subsection{Theoretical Review}

\subsubsection{Resource-Based Theory (RBT)}

The Proponents of RBV include Penrose (1959), Wernerfelt (1984), Barney (1991), Prahad and Hamel (1990). Edith Penrose contributed to the RBV field as early as 1959 when she argued that a firm is more than an administrative unit; that it is a collection of productive resources, the disposal of which between different users and overtime is determined by executive decision. Penrose Stated further that when the function of the private business firm is regarded from this point of view, the size of the firm is best gauged by some measure of the productive resources it employs. Wenerfelt (1984), in his contribution, coined the term resourcebased view in 1984. According to RBV proponents, it is much more feasible to exploit external opportunities using existing resources in a new way rather than trying to acquire new skills for each different opportunity. The RBV model gives resources to a significant role in helping companies to achieve higher organisational performance. These proponents contend that the main sources of competitive advantage are proactively created and maintained by firms through acquiring and accumulating their strategic resources.

The Resource-Based View (RBV) analyzes and interprets internal resources of the organisations and emphasizes resources and capabilities in formulating a strategy to achieve sustainable competitive advantages. Resources may be considered as inputs that enable firms to carry out their activities. Internal resources and capabilities determine strategic choices made by firms while competing in their external business environment. Firm's abilities also allow some firms to add value in the customer value chain, develop new products or expand in the new marketplace. The RBV draws upon the resources and capabilities that reside within the organisation to create sustainable competitive advantages. According to RBV, not all the resources of the firm will be strategic 
and hence, sources of competitive advantage. Competitive advantage occurs only when there is a situation of resource heterogeneity and resource immobility. Barney (1991) pointed out that the RBV explains that the internal resources, assets, capabilities and knowledge of a firm are the critical determinants of the competitive position of the firm.

\subsubsection{Dynamic Capability Theory}

The DCT was initially introduced by David Teece and Gary Pisano in 1994. According to (Teece \& Pisano, 1994), in the past successful companies pursued a "resource-based strategy of accumulating valuable technological assets, often reserved by a defensive approach towards intellectual property". Das and Teng (2000) reported that the "resource-based strategy" was grounded on the ideas of the "Resource-Based View" which attempted to explain that the source of competitive advantage lies within a company's ability to manage internal resources. The argument is that because some resources can be specific to firms and are not easily imitated, firms differ in terms of their resource base. This inimitability is essentially what leads to competitive advantage. At the heart of the RBV are the VRIN variables.

Bowman and Ambrosini (2003) opined that the main principle is that an organization is seen as a collection of resources that are simultaneously valuable, rare, imperfectly imitable and non-substitutable, these variables essentially enable the company to reap superior rents. In this context, the resource-based view focuses on the unique internal resources within firms and exploiting firmspecific assets to achieve competitive advantage. Although the Resource-Based View is considered an influential management theory it has been criticized to be conceptually vague and redundant, with limited focus on the mechanisms by which resources contribute to competitive advantage. This is supported by Teece and Pisano (1994), who argued that the foundation of the resource-based view is not capable of supporting sustained competitive advantage.

The DCT expands on two fundamental issues that were not discussed in other strategy approaches, such as the resource-based view; the first being the firm's ability to renew competencies to adapt to changes in the business environment and the second being the ability of strategic management to use these competencies to match the requirements of the environment. Thus, Eisenhardt and Martin (2000) opined that the resource-based view has not been able to adequately explain how and why individual firms have a competitive advantage in situations of rapid and unpredictable change in which DC's become the source of sustained competitive advantage, the DC's approach is proposed. In this sense, the DCT adds to the resource-based view by attempting to improve theory by explaining the nature of sustainable competitive advantage, while also intending to inform managerial practices.

\subsection{Empirical Review}

\subsubsection{Penetration Strategy and Market share}

Empirically, different studies have been carried out on penetration and market share. A study on Market Penetration Strategies and Market Share of Mobile Tele-communications Service providers in Kenya done by Gacheo, Thuo and Byaruhanga (2016) revealed that Market Penetration Strategy had a direct bearing on organizational competitiveness and market share in that higher penetration rates imply better performance since the firm can generate and sustain profits that are more prominent than the normal for that industry. Furthermore, Wainaina and Oloko (2016) study investigated the influence of Strategies for market penetration and organisational growth: a soft drink case. The stratified random sampling technique has been used. The research randomly chose a sample of 160 soft drink businesses. Data were collected and analyzed using both descriptive and inferential statistical tools. Correlation analysis was used to identify the authority and direction of the two variables linear relationship. The findings showed a connection between Penetration Policies and Organisational Development. Pricing strategy for penetration has been negative and has no powerful effect on the development of the organisation. The study concluded that all the Market Penetration Strategies are essential for organizational growth and that every one of them supplements one another and ought to be incorporated in the marketing plan for an organization to increase its market share/market penetration and organizational growth. However, the study context was a Case of Soft Drink. Mwiti (2011) investigated the use of Market Penetration approaches by Essar Telecom Kenya. The investigator used primary and secondary data gathered using questionnaires and schedules for interviews from managers in 5 functional units. The research also discovered that Pricing Strategies were used by the business to penetrate the market. It also found that the company undertakes Market Segmentation as one of the ways of expanding its market share.

A study by Chandola and Fu (2017) examined China Smartphone Companies ' market penetration approach for India Market: A multi-case research. Following the most common methodology of multi-case study methodology construction theories, distilled research results on the effective set of marketing policies from interviews with executives of four famous Chinese cell phone manufacturers/brands entering the Indian market. Similarities in the company's business models were quite evident in the results linked to their customer segment(s) strategy of creating innovative products that could afford them. The findings have also been shown to a remarkable extent resemblance in their conduct concerning customer relationship management.

\subsection{Theoretical Framework}


Given the theories explained above, the Dynamic Capabilities Approach is adopted here due to its advantage over the ResourceBased View and other theories reviewed in focusing on both internal and external factors that are dynamic enough in creating improved performance and competitive advantage. Whereas the resource-based view focuses more on aspects that are internal to the firm, the dynamic capabilities concentrate on factors that are both internal and external and can be reconfigured to meet up with internal and external expectations. Augier and Teece (2009) suggested that dynamic capabilities have a tripartite structure: the capability to sense opportunities; the capacity to seize opportunities; and the capacity to manage threats through combination, recombination and reconfiguration of assets inside and outside the enterprise's boundaries which informed this research. With Dynamic Capabilities, sustained operational performance comes from the firm's ability to leverage and reconfigure its existing competencies and assets in ways that are valuable to the customer but difficult for other competitors to imitate.

For organizations to be able to adopt effect growth strategies and profit from them, there needs to be some sort of dynamism in their approach if they want to improve. This is where the idea of dynamic capabilities comes to play as they begin to sense, seize and reconfigure their resources and capabilities to be able to penetrate and develop their markets, create new products and diversify eventually. This here gives credence to the suitability of the dynamic capabilities theory over other theories that have been reviewed, although they are relevant. Dynamic capabilities help firm's sense opportunities and then seize them by successfully reallocating resources, often by adjusting existing competencies or developing new ones.

Teece, Pisano and Shuen (1997) opined that the Dynamic capabilities extend the RBV by examining the sources of competitive advantage in rapidly changing markets and refer to firms' abilities to 'integrate, build, and reconfigure internal and external competencies to address rapidly changing environments. According to Teece (2010), the dynamic capabilities framework helps identify the factors that impact firm performance, and as a result, is gradually developing into a theory of the modern organisation. This framework offers a comprehensive, multidisciplinary approach to managerial decision-making. Dynamic capabilities include strategic and Organisational processes, such as product development, alliance formation and strategic decision making, which are deeply embedded in firms. Eisenhardt and Martin (2010) argued that the performance of the dynamic capabilities' theory varies across firms due to differential capacities of firms to integrate, utilize, renew, and reconfigure resources in response to the changing environment.

\subsection{Conceptual Model}

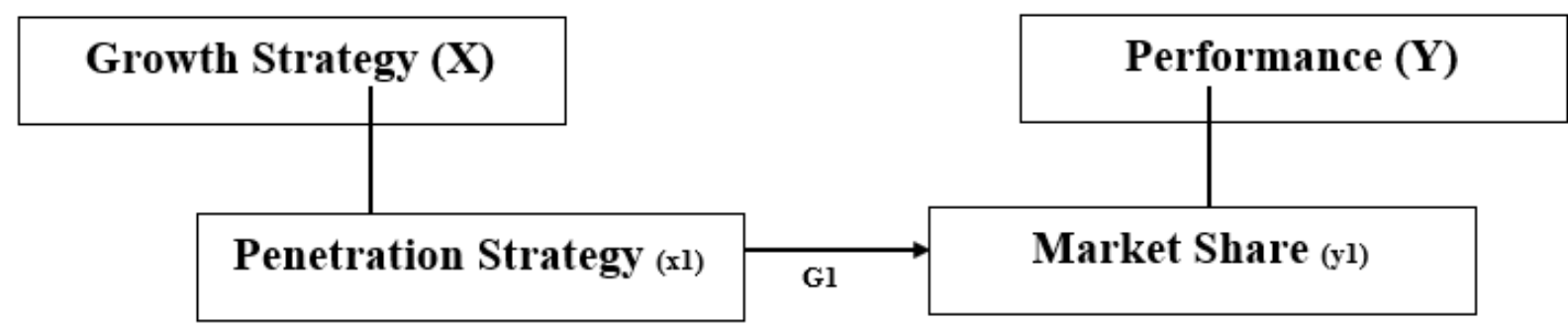

Fig 1- Researcher's Conceptual model

\subsection{METHODOLOGY}

The study employed a cross-sectional survey research design. The cross-sectional survey research design was adopted to obtain information from the focus population concerning the current status of the phenomena through primary data collection. The population for the research comprised of selected Small and Medium Scale Enterprise that were registered with SMEDAN, which were operating in Anambra State, Nigeria. The total number of registered SMEs with SMEDAN as of 2017 was 1,504. The sample size for the study was obtained using the research advisors table. Based on a confidence level of 95 and the level of precision of $5 \%$ the samples size was 322, with the addition of $30 \%$ for non-response rate, the sample was given thus as 418 . The addition of $30 \%$ to the sample size was to ensure that the response rate of the study was attained significantly. Making provision for the non-response rate allows the researcher to improve the rate of response for the survey [37] 


\subsection{RESULTS AND DISCUSSION}

Table 4.1: Summary of linear regression analysis for the effect of penetration strategy on the market share of selected small and medium scale enterprises in Anambra State.

\begin{tabular}{|c|c|c|c|c|c|c|}
\hline Variables & $B$ & $T$ & Sig & $R$ & $R^{2}$ & $\begin{array}{l}\text { Std. Error of the } \\
\text { Estimate }\end{array}$ \\
\hline Constant & 7.276 & 8.204 & .000 & \multirow[t]{2}{*}{$.673^{\mathrm{a}}$} & \multirow[t]{2}{*}{.452} & \multirow[t]{2}{*}{3.246} \\
\hline PENETRATION & .684 & 18.086 & .000 & & & \\
\hline \multicolumn{3}{|c|}{ a. Dependent Variable: MARKET SHARE } & \multicolumn{4}{|c|}{$\mathrm{F}(396,1)=327.118$} \\
\hline
\end{tabular}

Table 4.1 reveals the result of the simple linear regression test that was carried out to test the effect of the penetration strategies on the market share of selected small and medium scale enterprises in Anambra State, Nigeria. The $r=0.673$ is the correlation coefficient which represents the strength and direction of the relationship between the penetration strategy and market share of the small and medium scale enterprises. The coefficient reveals that there is a positive relationship between the penetration strategy and the market share of the selected small and medium scale enterprises. Furthermore, it can be concluded that there is a medium relationship between the two variables. Concerning the exact effect of the penetration strategies on market share, the $r^{2}=0.452$ shows the extent to which the penetration strategy explains the variation in market share of the selected small and medium scale enterprises. The implication here is that the penetration strategies explain $45.2 \%$ of the variations that occur in the market share of the selected small and medium scale enterprises. The p-value for the analysis was reported as less than the alpha benchmark of 0.05 thus implying that the analysis done, was statistically significant and, on that basis, the null hypothesis one that was formulated will be rejected and we conclude that the penetration strategies significantly affect the market share of the selected small and medium scale enterprises in Anambra State, Nigeria.

\subsection{Discussion}

The test of hypothesis revealed that penetration strategy has a significant effect on the market share of the selected small and medium scale enterprises in Anambra state. In line with the provisions of literature, this finding aligns with other studies, conceptually, theoretically and empirically. Conceptually, the linkage between penetration and market share was provided through definitions of the variables. Market penetration is one of the Igor Ansoff growth strategic decision, that is aimed at creating more shares for the existing market [53]. The strategy concentrates on gaining market competitiveness by having a sustainable market share in the market [17]. Market penetration is a process in which the firm influence its strategies to increase its business activities, through maintaining sales to current customers as well as looking for a potential customer to increase the volume of sales, without changing its prime market and product strategy. On the other hand, market share is the percentage of the total sales volume in a market captured by a brand, product, or company.

Empirically, the finding aligns with the provision of the findings of other research There was a connection between Penetration Policies and Organizational Development, according to the findings. The pricing strategy for penetration has been negative and has had little impact on the organization's growth. The study found that all Market Penetration Strategies are important for organizational development, and that each one complements the others. They should all be included in a company's marketing strategy if it wants to increase market share/market penetration and expand Wainaina \& Oloko (2016), on the other hand, conducted a report on market penetration strategies and organizational growth in Kenya's soft drink industry, and their results confirmed that pricing and distribution strategies had negative effects on organizational growth and market share. Geographical variations, as well as differences in methodological approaches to data collection and interpretation, may be the reason for discrepancies in the results.

Theoretically, the findings in this study aligns with theoretical provisions especially with that of the theory that was adopted as the anchor theory for the study. Related to this, Augier and Teece (2009) proposed a three-part framework for dynamic capabilities: the ability to sense opportunities, the ability to capture opportunities, and the ability to handle risks through the combination, recombination, and reconfiguration of assets inside and outside the enterprise's boundaries, which influenced this study. 
Sustaining operating efficiency with Dynamic Capabilities stems from the firm's ability to optimise and reconfigure its existing competencies and assets in ways that are beneficial to the consumer but impossible for rivals to emulate.

To be able to implement effective growth strategies and benefit from them, companies must have some dynamism in their strategy if they want to improve. This is where the concept of dynamic capabilities comes into play, as they begin to detect, capture, and reconfigure their resources and capabilities in order to penetrate and improve their markets, produce new goods, and gradually diversify. This lends credence to the suitability of the dynamic capabilities theory over other theories that have been tested, despite the fact that they are applicable. Dynamic skills enable firms to detect and capitalise on opportunities by successfully reallocating resources, often by adapting existing competencies or creating new ones.

\subsection{CONCLUSION AND RECOMMENDATION}

The study determined the effect of growth strategy and SME performance of selected small and medium scale enterprises in Anambra state, Nigeria. In view of the empirical findings of the study, this study concludes that growth strategy (market penetration) had significant effect on the performance (Market Share) of small and medium enterprises SMEs in Nigeria. The study revealed that penetration strategy has a significant effect on the market share of the selected small and medium scale enterprises in Anambra state. The study recommends that Penetration strategies should be given adequate attention and consideration by different small and medium-sized enterprises to reap benefits. Penetration strategies which are an effective tool for achieving better performance over rivalry firms should be adequately implemented by the organization.

\subsection{Limitations of the Study}

There are several limitations to the study. The methodology used for this research which includes; the research design chosen, survey research design and confidentiality for respondents. Some of the respondents tend to hold back some information and not provide correct responses to questions because they are not sure of the outcome of the research. Few of the SMEs not quick to grant easy access for questionnaires administration due to issues bordering on the security of the owners. The limitation of simple regression analysis is the nature of the data used. Too often analyses are carried beyond justifiable inference into assertions for which there is no sound defence leading to errors of judgment.

The data collection method that was used in this study was another limitation. The data collection was primary and is based on the use of a questionnaire as a research tool with some limits identified. Since the questionnaire was close-ended, there was no avenue for the respondents to give inputs and or make changes the items of the questionnaire.

The researcher managed the limitations identified as follows; in the case of confidentiality of respondents, the researcher held the respondents in high esteem and did not divulge information provided by them for any other purpose other than the research purpose. By using the services of a research assistant to help educate them on the significance of the research, the researcher was able to address this limitation and convince them to correctly fill out the questionnaire and return it on time.

\subsection{Suggestions for Further Studies}

The findings of this study suggest several areas for future research so as to enrich the research scope and to overcome the limitation of the study; the researcher suggests the need for further studies to include the following:

- This study was carried out on selected small and medium-sized enterprises in Anambra State, future research should examine the research variables in other geographical locations and research context, so as to increase the generalizability of the findings.

- One of the shortcomings of cross-sectional research design is that information or data are collected only once at different location. Future research could carry out this study using longitudinal research design, which takes into cognizance performance over a period of time.

- Further research is needed also to examine whether the findings of this study are applicable to other sectors of the Nigerian economy and other countries and extending the research by integrating other variables such as firm characteristics and competitive environment.

\section{REFERENCE}

1. Al-Kalouti, J., Kumar, V., Kumar, N., Garza-Reyes, J.A., Upadhyay, A., Zwiegelaar, J.B., \& Kumari, A. (2019). Investigating innovation capability and organisational performance in service firms. Strategic Change: Briefings in Entrepreneurial Finance. (In press).

2. Ansoff, H. I., Kipley, D., Lewis, A. O., Helm-Stevens, R., \& Ansoff, R. (2019). Strategic Issue Management. In: Implanting Strategic Management. Palgrave Macmillan, Cham. 
3. Armstrong, C. E. (2013). Competence of flexibility? Survival and growth implications of competitive strategy preferences among small US businesses. Journal of Strategy and Management, 6(4), 377-398.

4. Bayaraa, B. (2017). Financial performance determinants of organizations: The Case of Mongolian Companies. Journal of Competitiveness, 9(3), 22-33.

5. Bianchi, C. (2012) Introducing SD modelling into planning and control systems to manage SMEs' growth: a learningoriented perspective. System Dynamics Review, 18(3), 315-338.

6. Burugo, V. M., \& Owour, D. (2017). Influence of strategic management practices on business profitability in Kenya. (A case study of Chai trading company limited). Imperial Journal of Interdisciplinary Research, 3(9), 923-947.

7. Caves, R. \& Porter, M. E. (2010). Frome entry barriers to Mobility Barriers: Conjectural Decisions and Contrived Deterrence to New Competition. Quarterly Journal of Economics, 91(2), 241-262.

8. Chandola, V. K., \& Fu, H. (2017). Market penetration strategy of Smartphone companies from China for India Market: A Multiple-case study. International Journal of Business Marketing and Management, 2(4), 10 -16.

9. Darmon, R., Duclos-Gosselin, L., \& Rigaux-Bricmont, B. (2013). A Measure of Dynamic Market Performance. American Journal of Industrial and Business Management, 3(2), 164-177.

10. Ebitu, E. T., Basil, G., \& Ufot, J. A. (2016). An appraisal of Nigeria's micro, small and medium enterprises: growth, challenges and prospects, International Journal of Small Business and Entrepreneurship Research, 4(4), 1-15.

11. Enida, P., Vasilika, K., \& Amali, C. (2015). The impact of competitive advantage on organizational performance. The evidence from Albanian context. European Scientific Journal.; 11(28), 273-285.

12. Eyenubo S. (2013). The impact of bigger board size on financial performance for firms: The Nigerian experience. Journal of Research in International Business and Management, 3(3), 85-90.

13. Farah, L., \& Nina, S. (2016). Factors Affecting Profitability of Small Medium Enterprises (SMEs) Firm Listed in Indonesia Stock Exchange. Journal of Economics, Business and Management, 4(2), 132-137.

14. Giacobbe, R. W., Jackson, D. W., Crosby, L. A., \& Bridges, C. M. (2006). A Contingency Approach to Adaptive Selling Behavior and Sales Performance: Selling Situations and Salesperson Characteristics. Journal of Personal Selling \& Sales Management, 26(2), 115-142.

15. Hambrick, D. C. \& MacMillan, I. C. (2009). The Product Portfolio and Man's Best Friend. California Management Review, 24 (Fall), 84-95.

16. Herath, H. M. A., \& Mahmood, R. (2013). Strategic orientation-based research model of SME performance for developing countries. Review of Integrative Business and Economics Research 2(1), 430-440.

17. Hutzschenreuter, T., Kleindienst, I., Groene, F., \& Verbeke, A. (2014). Corporate strategic responses to foreign entry: insights from prospect theory. The Multinational Business Review, 22(3), 294-323.

18. Junaidu, M. K., \& Hauwa, S. (2018). Corporate Tax and Financial Performance of Listed Nigerian Consumer Goods. Journal of Accounting and Financial Management, 4(4), 30-43.

19. Kairu E. W., Wafula, M. O., Okaka, O., Odera, O., \& Akerele, E. K. (2013). Effects of Balanced Scorecard on Performance of Firms in the Service Sector. European Journal of Business and Management, 5(9), 81-83.

20. Kaushal, H., Karki, B., \& Singhal, B. (2017). GST: It's impact on economic growth and trade of India with special reference of MSMEs. EPRA International Journal of Economic and Business Review, 7(4), 35-39.

21. Kazooba, C. T. (2017). Causes of small business failure in Uganda: a case study from Bushenyi and Mbarara Towns. African Studies Quarterly, 8(4), 27-35.

22. Koech, A. K., \& Were, S. (2016). Factors influencing strategy implementation at the National Treasury-Kenya. The Strategic Journal of Business \& Change Management, 3(4), 269-288. 
23. Kondakci, Y., Kurtay, M.Z., Beycioglu, K., Sincar, M \& Ugurlu, C.T. (2016). The mediating roles of internal context variables in the relationship between distributed leadership perceptions and continuous change behaviours of publicschool teachers. Educational Studies 42(4):1-17

24. Kyalo, R. (2016). Growth Strategies and Performance of Large Oil Companies in Kenya. A Master's Thesis. University of Nairobi.

25. Levay, P. Z., Drossinos, Y., \& Thiel, C. (2017). The effect of fiscal incentives on market penetration of electric vehicles: A pairwise comparison of total cost of ownership. Energy Policy, 105, 524-533.

26. Li, N. \&, \& Dimitratos, P. (2014). How do business-level strategies affect multiple market servicing modes in the foreign country? International Marketing Review, 31(5), 526-546.

27. Majama, N. S. \& Magang, T. I. T. (2017). Strategic planning in Small and Medium Enterprises (SMEs): A case study of Botswana SMEs. Journal of Management and Strategy, 8(1), 74-103.

28. Makanga, R. O. \& Paul, S. N. (2017). Influence of strategic management practices on performance of Kenya power and lighting company ltd., Nairobi County, Kenya. The Strategic Journal of Business \& Change Management, 4(4), $289-306$.

29. Masood, U. H., Saif, U. Q., Sidra S., \& Aamna, M. (2013). Impact of marketing strategy creativity on organizational performance via marketing strategy implementation effectiveness: Empirical Evidence from Pakistani Organizations. Middle-East Journal of Scientific Research, 16(2), 264-273.

30. Mckeown, M. (2011). The Strategy Book: How to think and act strategically for outstanding results (2nd ed.). New York: FT Publishing.

31. Mwiti, L. K. (2011). Market penetration strategies used by Essar telecom Kenya (yu). (Doctoral dissertation, University of Nairobi).

32. Ngoc-Tan, N., \& Gregar, A. (2019). Knowledge management and its impacts on organizational performance: an empirical research in public higher education institutions of Vietnam. Journal of Information and Knowledge Management,

33. Odunayo, O. A. (2018). Market Focus Strategy and Organizational Performance of Telecommunication Companies in Port Harcourt. International Journal of Innovative Research and Advanced Studies, 5(3), 258-263.

34. OECD (2004). Promoting Entrepreneurship and Innovation SMEs in a Global Economy: Towards a More Responsible and Inclusive Globalization. Retrieved from https://www.oecd.org/cfe/smes/31919590.pdf

35. Ojwaka, A. S., \& Deya, J. (2018). Effect of Growth Strategies on Organizational Performance: A Survey of Commercial Printing Firms in Nairobi, Kenya. The Strategic Journal of Business \& Change Management, 5(4), 251-266.

36. Okwo, I. M. (2012). Investment in fixed assets and firm profitability: Evidence from the Nigerian Brewery industry. European Journal of Business Management, 4(20), 10-17.

37. Onamusi, A. B. (2020). Strategic capability and firm competitiveness: How Omoluabi leadership makes a difference. Business excellence and management, 10(4), 23-37.

38. Osotimehin, K. O., Jegede, C. A., Akinlabi, B. H., \& Olajide, O. T. (2012). An evaluation of the challenges and prospects of micro and small-scale enterprises development in Nigeria. American International Journal of Contemporary Research, 2(4), 174-185.

39. Pearce, J. A. \& Robinson, R. B. (2011). Strategic Management: Formulation, Implementation, and control, (12th ed.). McGraw Hill.

40. Pelin, V., Yalcin, V., Ozgur, Y., \& Burcu, Y. (2013). Impacts of Growth Strateegies on Human Policies. Procedia Social and Behavioural Sciences, 99, 861-868.

41. Penrose, E. (2016). The theory of the growth of the firm. Campinas: Editora da Unicamp.

42. Rao, H. M., \& Zaidi, U. (2019). How different Perceived Leadership Styles have an influence on Organisational Commitment on Tourism SMEs? African Journal of Hospitality, Tourism and Leisure, 9(1), 1-16. 
43. Reuben, J. M., Obura, J., \& Oginda, M. (2019). Mediation effect of system success features on open source erp adoptionuse and organisational performance. Global Scientific Journals, 7(5), 660-667.

44. Reza, S., Amir, H. N. \& Mohammad, V. (2016). The Effect of Competitive Intelligence on Organizational Performance Through Orientation (Case Study: Insurance Companies Sanandaj). Asian Journal of Information Technology, 18, 250260.

45. Schwalbach, J. (2018). Profitability and Market Share: A Reflection on the Functional Relationship. Strategic Management Journal, 12 (May), 299-307.

46. Shafiq, M., Lasrado, F., \& Hafeez, K. (2019). The effect of TQM on organizational performance: empirical evidence from the textile sector of a developing country using SEM. Total Quality Management \& Business Excellence, 30(1-2).

47. Sidi, A. B., Haim, A. H., \& Abdul, B. M. (2017). The impact of market penetration strategy and market development strategy on the competitive advantage of manufacturing-based SMEs. In: 4th Conference on Business Management, 29 30 October 2017.

48. Sije, A. \& Oloko, M. (2013). Penetration Pricing Strategy and Performance of Small and medium Enterprises in Kenya. European Journal of Business and Social Sciences, 2(9), 114-123.

49. Slater, S. F., \& Narver, J. C. (2016). Competitive strategy in the market-focused business. Journal of market-focused management, $1(2), 159-174$.

50. Sliden, K. (2017). Marketing Intelligence. Economic Trends.

51. Stubbs, W. (2019). Strategies, practices, and tensions in managing business model innovation for sustainability: The case of an Australian BCorp. Corporate Social Responsibility and Environmental Management, 26, 1063- 1072.

52. Uchegbulam, P., Akinyele, S., \& Ibidunni, A. (2015). Competitive Strategy and Performance of Selected SMEs in Nigeria. In International Conference on African Development Issues: Social and Economic Models for Development Track (326-333).

53. Uko, J. P., \& Ayatse, F. A. (2014). Market Penetration as a Growth Strategy for Small and Medium-Sized Enterprises in Nigeria. Management and Administrative Sciences Review, 23(January), 8-23.

54. Wainaina, G., \& Oloko, M. (2016). Market Penetration Strategies and Organization Growth: A Case of Soft Drink Sector in Kenya. International Journal of Management and Commerce Innovations, 3(2), 219 -227.

55. Wanjiru, B., \& George, G. E. (2015). Analysis of Organic Growth Strategies on Performance of small and medium sized Enterprises: Case of Thika Sub-County, Kenya. European Journal of Business and Management, 7(5), 180-205.

56. Woo, C. Y., \& Cooper, A. C. (2011). Strategies of Effective Low Share Businesses. Strategic Management Journal, 2(3), 301-318.

\section{Email address}

\section{${ }^{1}$ NWAELE, SYLVESTER KELECHI}

Email: ${ }^{1}$ Nwaelesylvester@gmail.com

${ }^{2}$ DR, EGBUTA OLIVE. U

Email: Egbutao@babcock.edu.ng

Management Science, School of Business

Babcock University, Ilishan Remo, Ogun State, Nigeria. 